\title{
Preliminary Findings Using Growth Mindset and Belonging Interventions in a Freshman Engineering Class
}

\section{Dr. Jinny Rhee, San Jose State University}

Dr. Jinny Rhee is the associate dean of the College of Engineering at San Jose State University. She oversees the undergraduate programs in the college, including curriculum, accreditation, student support, and outreach. In addition to engineering education, her research interests include thermal management of heat and power systems. Dr. Rhee received a PhD in mechanical engineering from Stanford University (1995).

\section{Prof. Camille Johnson, San Jose State University}

Camille Johnson is a professor of management in the Lucas College and Graduate School of Business at San Jose State University. She has a PhD in social psychology from Ohio State University and studies first generation students and diversity issues.

Dr. Clifton M. Oyamot Jr., San Jose State University 


\title{
Preliminary Findings Using Growth Mindset and Belonging Interventions in a Freshman Engineering Class
}

\begin{abstract}
Engineering is typically plagued with lower graduation rates and larger achievement gaps compared to other majors; the projected demand for its future graduates lends to the urgency in reversing these trends. Holding a growth mindset, or a belief that intelligence is mutable, and a feeling of belongingness are keys to persisting in and graduating from college. In prior research, improvements in retention and graduation rates have been found following minor interventions, particularly among some underrepresented populations of students. The current study explored whether similar interventions could be effective in increasing retention and graduation rates among underrepresented populations of engineering and technology majors. It was conducted in an engineering college in a large, comprehensive, Hispanic-Serving, public university with a sizeable Asian population (40\%), and 10-20\% gap in the graduation rates of underrepresented and non-underrepresented minorities. The engineering college has a low percentage of women undergraduates (15\%) and graduations rates for women are 5-10\% higher than those of men. The results of this study may be applicable to other engineering schools with similar characteristics.
\end{abstract}

Following IRB approval, a control assignment or interventions designed to elicit a growth mindset and/or a belongingness mindset were administered in 25 sections of a required Introduction to Engineering course (441 students total), typically taken in the freshman year of all engineering-named and technology programs. Block randomization was used to distribute, as evenly as possible, the gender, ethnic background, and section instructor composition across conditions. Pre- and post-course surveys measured happiness, health, belonging, self-efficacy, and growth mindset, and student grades were collected at the end of the academic term. One year into a 6-year study in which students will be tracked through graduation, preliminary results suggest that the interventions can aid performance. Overall, students who received the belongingness intervention had higher average class grades than those in the control and growth mindset condition, controlling for instructor, HS GPA, and SAT math scores. Further analyses revealed that the interventions had different effects on different demographic groups. First, among women, the growth mindset intervention resulted in lower course performance compared to the control and belongingness groups. Second, among men, the belongingness intervention resulted in higher course performance than in the growth and control. Third, the interventions did not differentially affect course performance among under-represented minorities (URMs). Finally, among non-URMs, the belongingness intervention led to improved course performance compared to the growth mindset and control conditions.

Interestingly, prior to the interventions, underrepresented minority students exhibited higher growth mindset scores (effect size $=0.32$ ) than non-underrepresented minority students and women exhibited higher feelings of belonging $($ effect size $=0.21)$ than men.

\section{INTRODUCTION}


The present work evaluates whether minimally-invasive, low-cost interventions fostering a growth mindset and/or feelings of belonging can be effective in impacting retention and graduation rates of engineering and technology majors at a large comprehensive public university with a significant minority population. The projected demand for engineering and technology graduates and the need to diversify the engineering workforce are societal impacts of this work. The context and objectives for this study are described below.

\subsection{Prior Work}

A variety of approaches to improving student success in engineering have been explored. Some approaches focus on improving skills and preparation, while others focus on motivation and other psychological factors. One widely accepted model is Tinto's Interactionist Model, which argues that students who integrate socially become more committed to the university and are thus more likely to be retained and to graduate ${ }^{1}$. Veenstra et al. present a freshman retention model specifically for engineering majors that suggests that pre-college characteristics and academic integration are equally important for first-year retention and ultimately, graduation, in addition to social integration into the campus and into the engineering profession ${ }^{2}$. Psychological interventions that help underrepresented and to some extent, all, students cope with threats to their identity show promise in overcoming these threats and consequently raising achievement ${ }^{3}$. The present research is built upon these models, and tests two psychological interventions that can be used to complement traditional educational reforms by changing students' subjective experience in school, delivering treatment messages without stigmatizing recipients, and reinforcing the effects of early intervention ${ }^{4}$. One intervention promotes the growth mindset, and the other promotes a sense of belonging.

Prior work has demonstrated both the means and the positive consequences of developing a sense of belonging in engineering populations at a variety of institutions. At the University of South Alabama, a freshman seminar course for computing majors was used to successfully promote the sense of belonging, measured by increased positive interactions with faculty and students $^{5}$. At the University of Queensland and Virginia Tech, a video-based virtual mentoring intervention was developed for low-achieving second-year engineering students to support students electing not to attend campus-sponsored advising interventions ${ }^{6}$. At the Colorado School of Mines, an ethnographic study found that low-income, first-generation students face specific barriers to feeling like they belong, including financial pressure, curriculum overload, lower family support, and lower confidence in technical skill, but that they could establish a sense of belonging in engineering when their prior knowledge and experiences were validated ${ }^{7}$. A case study at the University of Maryland at College Park revealed that mismatches between students' epistemological identities and the intellectual climate influence the decision to leave or stay in engineering ${ }^{8}$. Engineering departments at the University of Washington found that the sense of belonging in women students is consistently higher in departments where they are represented in higher numbers ${ }^{9}$. At Arizona State University, the long-term effects to a suite of strategies designed to increase sense of belonging were found to be an increase in retention from $0.9 \%$ per year to $1.6 \%$ per year in their undergraduate engineering cohorts from 1998 to $2013^{10}$. Four areas were identified at the University of Washington as being important to the 
development of community and belonging of ethnic minority students: co-curricular activities, peer support, faculty/department support, and residence programs. They found that support mechanisms changed with time and responsive strategies should reflect that ${ }^{11}$. Sophomore and junior level engineering students at the University of Washington Seattle exhibited increase sense of belonging as they become more invested in their community of practice ${ }^{12}$.

In addition to feeling a sense of belonging with a field and institution, research suggests that believing intelligence and performance is malleable has positive consequences for performance. These beliefs about intelligence constitute a growth mindset, as first described by Carol Dweck from Stanford University ${ }^{13}$ in her work on implicit theories of intelligence. Her work shows that people who believe that intelligence is an innate and immutable characteristic are less likely to succeed than people who believe that intelligence can be developed through effective strategies and hard work. In addition, her work shows that a growth mindset can be engendered in individuals.

Strategies to encourage a growth mindset in computer science (CS) have had mixed results. On the one hand, strategies useful in general education populations have not been successful in CS contexts. One multiple-institution study asked students to advise other computer science students who learning to program in a way to promote a growth mindset, and produced guidelines for student advice based on student beliefs ${ }^{14}$. The study found that the act of giving advice may be even more valuable than receiving it. In a similar study, a "saying is believing" intervention that successfully promoted the growth mindset in non-CS contexts did not result in increases in growth mindset in a computer science population ${ }^{15}$. In yet another context, the mindsets of students in an introductory programming class became more fixed throughout instruction, and that a mindset for programming aptitude had greater utility in predicting software practice ${ }^{16}$.

Innovative teaching methods, such as design experiences, can also encourage a growth mindset. Research at Ohio Northern University indicates that the introduction of open-ended design projects in an engineering program can lessen or eliminate the predictable shift towards a fixed mindset that typically occurs in the first year of college ${ }^{17}$.

There is evidence that subtle psychological interventions can be self-reinforcing under certain conditions. A self-affirmation intervention designed to lessen stereotype threat to minority students resulted in a $40 \%$ reduction in the racial achievement gap ${ }^{18}$. Two years later, the improvements to performance and to self-perceptions had continued despite no reinforcement ${ }^{19}$. The effects of psychological interventions often decay or even reverse; however, the authors of the cited studies hypothesize in environments with chronic evaluation (such as school), performance gains can magnify and reinforce the intervention. Furthermore, by interrupting early failure, the typical loss of self-confidence and the resulting magnification of poor performance can be averted.

\subsection{Demographics and Graduation Rates}

San Jose State University (SJSU) is part of the 23-campus California State University, the largest public university system in the US. The College of Engineering is one of seven colleges at 
SJSU, and currently has 4757 undergraduate majors. Fig. 1 illustrates the ethnic composition of the undergraduate students in the college in Fall 2015; the three largest groups are Asian (39\%), Hispanic (21\%), and White (20\%). Fig. 2 shows that women comprise about $17 \%$ of the undergraduate population in the college in Fall 2015.

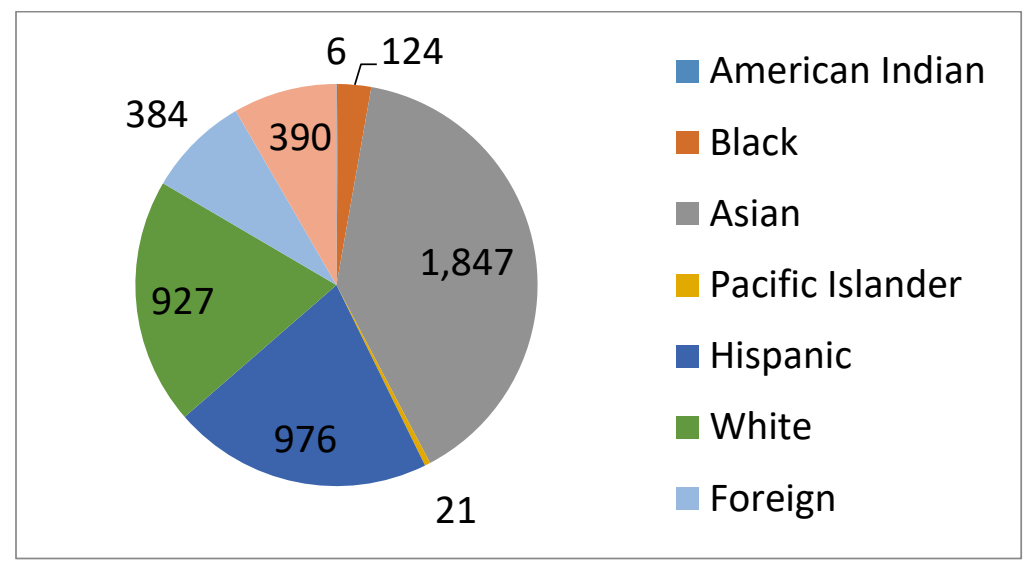

Fig. 1. Ethnicity in undergraduate programs in the College of Engineering at SJSU, Fall 2015

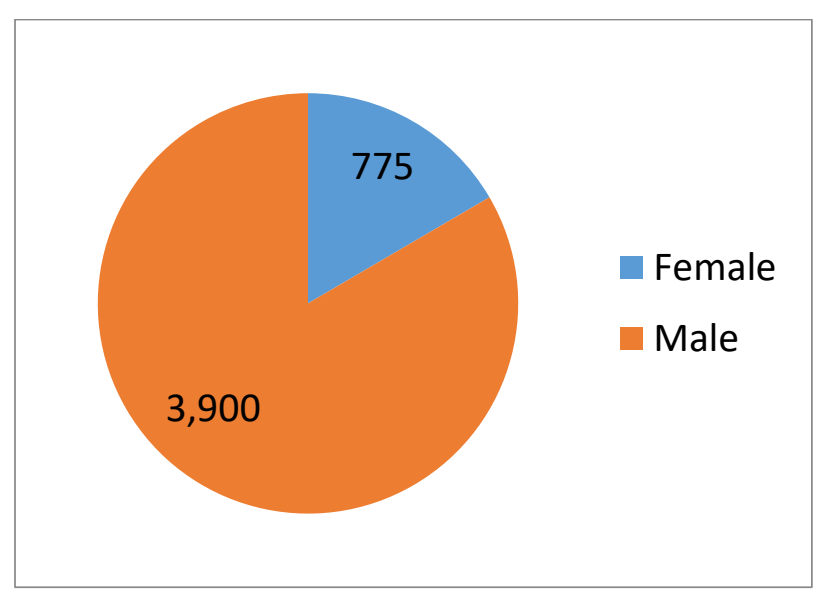

Fig. 2. Gender in undergraduate programs in the College of Engineering at SJSU, Fall 2015

The six-year graduation rates for freshmen in the College of Engineering vary significantly by ethnicity and gender. As shown in Fig. 3, the college average for all freshmen varies between $39 \%$ and $46 \%$. Women students generally graduate at higher rates than men, by as high as $10 \%-$ $20 \%$ in some years. This reverse achievement gap can sometimes be found in male-dominated fields when the percentage of women is particularly low such as in our college, and may indicate that the women students who do manage to prepare, apply, and be accepted to a non-traditional choice of major are exceptionally motivated and have overcome barriers to do so already. The underrepresented minority (URM) students are comprised of the African American, Hispanic/Latino, and Pacific Islander students. The URM freshmen typically graduate at rates between $17 \%$ to $24 \%$ lower compared to our non-URM students. Because of these gaps, the top priorities for our college include increasing graduation rates for all students and eliminating the achievement gap between URM and non-URM students. 


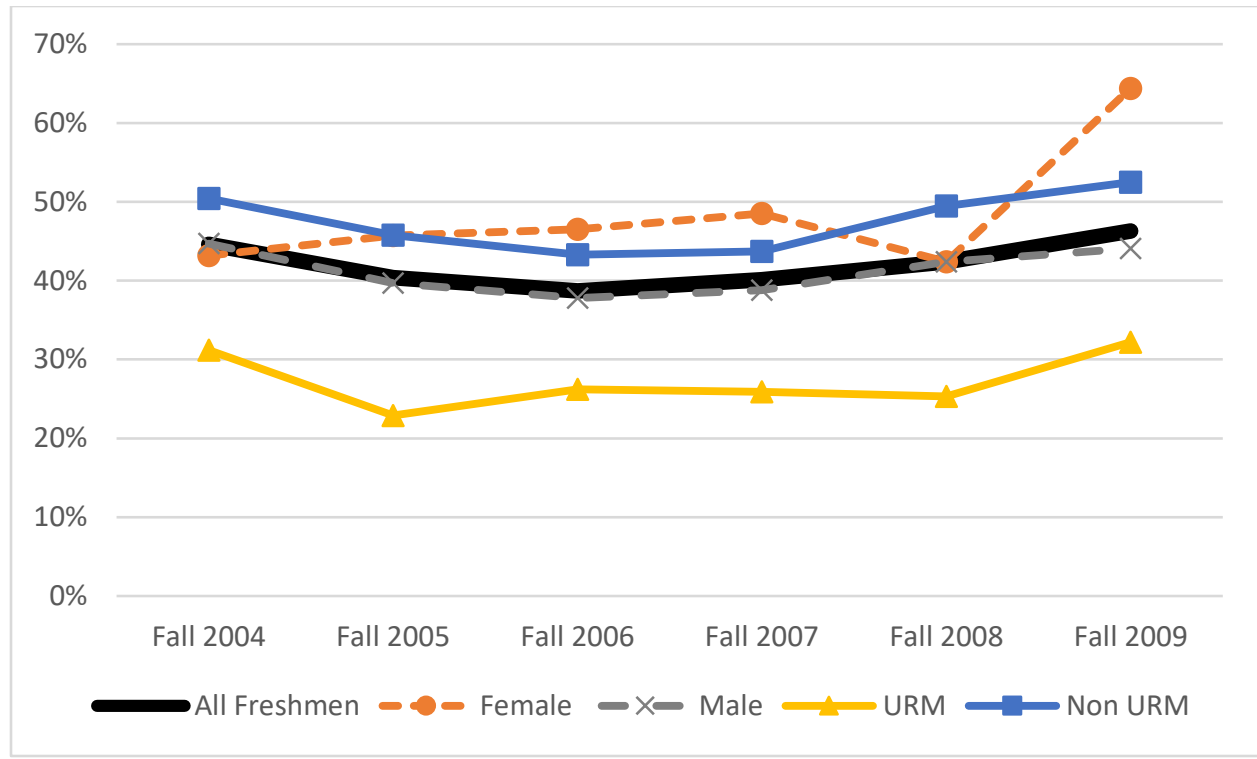

Fig. 3. Six-year graduation rates for entering freshman cohorts by gender and underrepresented minority status in the College of Engineering at LWPU.

\subsection{Objectives of Current Study}

The prior work on growth mindset and belonging interventions has predominantly been conducted at universities that differ from San Jose State University in demographic characteristics and mission; furthermore, the effectiveness of growth mindset and belonging interventions in STEM or engineering programs in particular and its minority populations is not well-known. The research questions we aim to answer for our student population are the following:

\section{$\underline{\text { Research Questions }}$}

1. Is the growth mindset intervention effective at increasing belief in the growth mindset in our freshman population?

2. Is the belonging intervention effective at increasing feelings of belonging in our freshman population?

3. Do either or both interventions enhance academic performance (e.g., course grades) of the students?

4. Do either or both interventions enhance academic performance (e.g., course grades) differentially across demographic groups in the study, (e.g., URM v. non-URM; women v. men)?

5. Do either or both interventions impact retention or even possibly graduation rates?

The current publication describes some preliminary results of the study regarding questions $1-4$ after the first semester of the study. In subsequent years we will be able to address question 5 .

\section{METHODOLOGY}


The interventions were administered during spring 2016 in the Introduction to Engineering course at San Jose State, which is a freshman-level required course for all engineering-named and technology majors. Students are required to attend one of two lecture sections with up to 250 students and a lab section with up to 25 students. The results described in this paper are from students entering in Fall 2015, therefore most of the students were in their second semester at LWPU.

The students received one of three interventions: 1) a control activity, 2) a growth mindset intervention, or 3) a belonging intervention. The lab section normally assigns a series of 13 assignments in which students are given a prompt and write a reflection essay. In the intervention groups, one of the reflection assignments was replaced with the intervention assignment. The students were separated into groups using block randomization by section, in which gender, URM/nonURM, and Pell-eligibility were distributed across conditions as equally as possible. The ethnic breakdown of the URM students is predominantly Hispanic, with very small percentages of Black and Pacific Islander students. Efforts were also made to balance condition assignment across lab section day of week, time of day, and instructor. The number of students in the corresponding conditions is indicated in Tables $1-3$.

Table 1. Demographic distribution of students in groups

\begin{tabular}{|l|l|c|c|c|c|}
\hline \multicolumn{2}{|c|}{} & \multicolumn{3}{|c|}{ Condition } & \\
\cline { 3 - 6 } \multicolumn{2}{|c|}{} & Control & Belonging & Mindset & Total \\
\hline \multirow{3}{*}{ Gender } & Women & 27 & 33 & 34 & 94 \\
\cline { 2 - 6 } & Men & 118 & 127 & 104 & 349 \\
\cline { 2 - 6 } & Total & 145 & 160 & 138 & 443 \\
\hline \multirow{3}{*}{ URM_status } & URM & 32 & 51 & 42 & 125 \\
\cline { 2 - 6 } & Non-URM & 113 & 109 & 96 & 318 \\
\cline { 2 - 6 } & Total & 145 & 160 & 138 & 443 \\
\hline \multirow{3}{*}{ Pell_status } & Pell-eligible & 59 & 63 & 63 & 185 \\
\cline { 2 - 6 } & Non-Pell & 86 & 97 & 75 & 258 \\
\cline { 2 - 6 } & Total & 145 & 160 & 138 & 443 \\
\hline
\end{tabular}

Table 2. Ethnic breakdown of URM students

\begin{tabular}{|l|c|c|c|c|c|c|}
\hline & Control & $\%$ & Belonging & $\%$ & Growth & $\%$ \\
\hline Black & 4 & $12.5 \%$ & 0 & $0.0 \%$ & 5 & $11.9 \%$ \\
\hline Pac Isl & 0 & $0.0 \%$ & 0 & $0.0 \%$ & 1 & $2.4 \%$ \\
\hline Hispanic & 28 & $87.5 \%$ & 51 & $100.0 \%$ & 36 & $85.7 \%$ \\
\hline Total & 32 & & 51 & & 42 & \\
\hline
\end{tabular}

Table 3. Lab section characteristics distribution in the groups 


\begin{tabular}{|l|l|c|c|c|}
\hline \multicolumn{2}{|c|}{} & Control & Belonging & Mindset \\
\hline Day & Monday & 0 & 0 & 0 \\
\cline { 2 - 5 } & Tuesday & 50 & 24 & 46 \\
\cline { 2 - 5 } & Wednesday & 23 & 40 & 21 \\
\cline { 2 - 5 } & Thursday & 48 & 48 & 47 \\
\cline { 2 - 5 } & Friday & 24 & 48 & 24 \\
\hline Time & Morning & 26 & 63 & 45 \\
\cline { 2 - 5 } & Afternoon & 95 & 97 & 69 \\
\cline { 2 - 5 } & Evening & 24 & 0 & 24 \\
\hline Instructor & B & 24 & 40 & 0 \\
\cline { 2 - 5 } & $\mathrm{D}$ & 26 & 24 & 44 \\
\cline { 2 - 5 } & $\mathrm{F}$ & 23 & 0 & 23 \\
\cline { 2 - 5 } & KD & 24 & 24 & 0 \\
\cline { 2 - 5 } & $\mathrm{S}$ & 24 & 24 & 0 \\
\cline { 2 - 5 } & $\mathrm{V}$ & 0 & 24 & 24 \\
\cline { 2 - 5 } & $\mathrm{WA}$ & 24 & 0 & 23 \\
\cline { 2 - 5 } & $\mathrm{WE}$ & 0 & 24 & 0 \\
\cline { 2 - 5 } & $\mathrm{Y}$ & 0 & 0 & 24 \\
\hline
\end{tabular}

In the present study we adapted a belonging intervention developed by Walton and Cohen ${ }^{20}$ which has been used successfully with STEM majors. The belonging intervention consists of a reading assignnment of excerpts from fictional seniors of various ethnicities and genders describing their integration into the university, followed by a reflection writing assignment. The minimal modifications made tailored the narrative to San Jose State and to engineering experiences. The group receiving the belonging intervention received it on Week 13 (out of a 16-week semester). The reason this week was chosen was merely that the normal reflection assignment assigned to the control group was most similar in topic, and that swapping it out for the intervention group posed the least disruption to the labs and instructors. The intervention can still influence students at this point in the semester - the projects and final exam have yet to be collected at this point in the semester.

The growth mindset intervention used in the present study was adapted from an intervention successfully implemented at San Jose State by the Statway and the Carnegie Foundation math remediation program ${ }^{21}$. The intervention required the students to read an article explaining that the brain is a muscle that gets stronger with regular practice, followed by a reflection writing assignment. The group receiving the growth mindset intervention received it on Week 8 (out of a 16-week semester). Similarly, the normal assignment during this week is most closely related to the topic of the intervention, and as such the intervention was administered this week in the growth mindset group.

Pre- and post-intervention surveys were administered in the lecture at the beginning (Week 1) and end of the semester (Weeks 15-16) to measure changes in growth mindset or feelings of belonging using established scales from the literature. 
The belongingness scale was obtained from Walton and Cohen ${ }^{19}$. It is comprised of seven questions which probe how connected respondents feel to the campus community and the engineering community. Respondents indicate their degree of agreement with each item using a 5 -point Likert scale $(1=$ strongly disagree to $5=$ strongly agree $)$. Responses to the items were found to be internally reliable (Cronbach's $\alpha=.88$ ). Responses across the seven items were averaged to form a single belongingness score.

The growth mindset scales were obtained from the Stanford University Project on Education Research that Scales (PERTS) website ${ }^{22}$. It is comprised of three questions which probe respondents' level of agreement to the fixed mindset. We implemented a 5-point Likert scale (1 $=$ strongly agree to $5=$ strongly disagree $)$. Responses to the items were found to be internally reliable (Cronbach's $\alpha=0.83$ ), and the responses across the three items were averaged to form a single growth mindset score.

Scales measuring happiness, self-perceived health, and self-efficacy were also included from this paper. While not the immediate focus of this study, they obscured the objective of the study to participants.

Academic performance measures were collected in the form of course grades at the conclusion of the semester.

Future work will include the longitudinal tracking of this student cohort to fully evaluate any impacts from our subtle interventions, as previously observed in the prior literature.

Informed consent and confidentiality of the participants were implemented for this study, in compliance with the Institutional Review Board (IRB) at our institution.

\section{RESULTS}

\section{Preliminary Analyses}

Previous academic performance. Before conducting our main analyses we performed a series of tests to determine whether there were significant pre-existing differences amongst our conditions that would affect the interpretation of our main results. No significant, systematic differences were detected.

We first conducted a series of one-way ANOVAs to determine whether there were significant pre-existing differences in HS GPA, SAT math scores, and ACT math scores (dependent variables) amongst our conditions (independent variable). The main effects for condition were not significant for the standardized test scores, $\left(F^{\prime} \mathrm{s}<2.80, n s\right)$, indicating that SAT and ACT math scores were equivalent across the conditions. The main effect for condition was significant for HS GPA $(F=3.08, p<.05)$, however post hoc Scheffe tests for each pairwise comparison of conditions showed just one marginal difference between the belonging $(M=3.55)$ and growth mindset $(M=3.43)$ conditions $(p=.07)$. In general, the conditions were equivalent on math and general academic skills, as measured by standardized test scores and HS GPA.

Disregarding condition, the average HS GPA score was $3.48(S D=0.37)$, average SAT math score was $588(S D=84)$, and average ACT math score was $25.63(S D=4.75)$. 
Belongingness and growth mindset. We also wanted to determine if there were significant differences in growth mindset, feelings of belongingness, or self-efficacy prior to the administration of the experimental manipulations, and found that there were none. We conducted a series of one-way ANOVAs with growth mindset, belongingness, and self-efficacy pretest scores as the dependent variables and none of the main effects for condition were significant, $(F$ 's $<0.50, n s)$.

Disregarding condition, the average belongingness score was 3.40, which corresponded to slightly above the mid-point on the 5-point Likert scale. The average growth mindset score was 3.50, which also corresponded to slightly above the mid-point on the 5-point Likert scale.

Some interesting differences between the subpopulations in our study were uncovered in the precourse survey. The women reported higher feelings of belonging (mean $=3.53)$ than the male students $($ mean $=3.37, \mathrm{p}=0.05$, effect size $=0.21)$. The URM students were more likely to have a growth mindset (mean $=3.72$ ) than the non-URM students (mean $=3.42, p=0.003$, effect size $=0.32$ ). This finding is inconsistent with some prior literature that posits that female students are less likely to feel like they belong in a male-dominated environment, and that URM students are less likely to have a growth mindset.

\section{Main Analyses}

\section{Research Questions 1 and 2}

To determine whether the growth mindset intervention was effective at increasing belief in the growth mindset (Research Question 1) and whether the belonging intervention was effective at increasing feelings of belonging (Research Question 2), we performed a series of one-way ANOVAs with posttest growth mindset and belongingness scores as the dependent variables and condition as the independent variable. The main effect of condition was not significant for either dependent variable $\left(F^{\prime}\right.$ 's $\left.<0.60, n s\right)$.

Although this result suggests that neither intervention was effective, other possible explanations include the following: 1) the lag time between the intervention and posttest measurement may have been too long for the posttest to capture it; 2) the scores for the growth mindset and belongingness scales were already high prior to the interventions, and there may be a ceiling effect; and 3) the interventions are subtle - it is not uncommon in prior studies for there to be no apparent intervention effects when measuring growth mindset.

\section{Research Questions 3}

Most fundamental to this investigation was whether either or both interventions enhanced academic performance (e.g., course grades) of the students (Research Question 3). To answer this question, we performed an ANCOVA with condition as the independent variable and grade earned in the engineering class as the dependent variable. Although we had established that prior academic performance did not differ across conditions, we opted to take a conservative approach and controlled for HS GPA and SAT math scores in the analysis by including them as covariates. 
The belongingness intervention was associated with the highest course grade point average. The main effect of condition was significant $(F=4.83, p<.01)$. Post hoc Scheffe tests for each pairwise comparison of conditions showed that average grade in the belongingness condition $(M$ $=3.13)$ was significantly higher than in the growth mindset condition $(M=2.72 ; p<.01)$, and marginally higher than in the control condition $(M=2.86 ; p=.07)$. The difference between control and growth mindset conditions was not significant.

\section{Research Question 4}

We further explored the possible intervention effects by considering whether the interventions were associated with course grades differentially across demographic groups in the study. We first examined possible gender differences using the same ANCOVA model described earlier. The analysis was performed separately for women and men. We then used the same procedure and separately considered under-represented minorities (URMs) and their counterparts (nonURMs)

Gender. Counter to expectations, for women the growth mindset intervention was associated with a detrimental effect on course performance compared to the belongingness and control conditions. The main effect of condition was significant $(F=4.78, p<.05)$. Post hoc Scheffe tests for each pairwise comparison of conditions showed that average grade in the growth mindset condition $(M=2.61)$ was significantly lower than both the belongingness condition $(M$ $=3.30 ; p<.01)$, and control condition $(M=3.17 ; p=.05)$. The difference between control and belongingness conditions was not significant.

In contrast, fostering a sense of belongingness in men was associated with enhanced course performance. The main effect of condition was marginal $(F=2.80, p=.06)$, but post hoc tests suggested some effects for the belongingness intervention. Post hoc Scheffe tests for each pairwise comparison of conditions showed that average grade in the belongingness condition $(M$ $=3.03)$ was significantly higher than in the growth mindset condition $(M=2.73 ; p<.05)$, and marginally higher than in the control condition $(M=2.80 ; p=.08)$. The difference between control and growth mindset conditions was not significant.

Under-represented minorities. For URMs, neither intervention was associated with course performance relative to the control condition; the main effect of condition was not significant $(F$ $<1.00, n s)$.

However, for non-URMs the belongingness intervention was associated with enhanced course performance. The main effect of condition was significant $(F=5.28, p<.01)$. Post hoc Scheffe tests for each pairwise comparison of conditions showed that average grade in the belongingness condition $(M=3.26)$ was significantly higher than in both the growth mindset condition $(M=$ $2.87 ; p<.01)$, and control condition $(M=2.91 ; p<.01)$. The difference between control and growth mindset conditions was not significant.

\section{CONCLUSIONS AND FUTURE WORK}

In summary, there were no increases in the growth mindset or belongingness scales as a result of the psychological interventions; however, we believe that they may still be having an effect 
based on the evidence that academic performance, measured by course grade, was improved in the group receiving the belonging intervention. We speculate that the growth mindset concepts are more prevalent today in K-12 (and college orientations); students may be gaining exposure to it prior to college, limiting the impact of further exposure. Belongingness, however, is a challenge faced at each transition in a student's life, and remains relevant in each new environment.

Among the subgroups in our study, the belonging intervention was associated with positive academic performance for men and non-URM students. The growth mindset intervention was associated with decreased academic performance for women, for unknown reasons. Neither intervention appeared to influence the URM students positively or negatively. This result is disappointing for us, and the use of these interventions for the purpose of closing the achievement gap remains elusive for us. If nothing else, this study contributes evidence towards the complexity of factors influencing performance and achievement gaps. For the time being, the growth mindset intervention has been discontinued in the class, while the belongingness intervention has been instituted for all sections.

We plan to track cumulative GPAs, units completed, retention, and possibly graduation rates of this cohort through the entire six year period of the study (or until differences dissipate). Some studies have registered long-term effects of subtle interventions, if administered at the right time and in the right environment. It is the hope that we will continue to register differences between the groups as the longitudinal study continues. Other future work may possibly include focus groups with some of the participants, or booster interventions if warranted by developing results.

\section{ACKNOWLEDGEMENTS}

We gratefully acknowledge the Provost Office at San Jose State University for funding this study under the 2015 Student Success Priority funding. Many thanks go to Dr. Lauren Aguilar and Dr. Chris Gonzalez Clarke at Stanford University for their consultation and expertise.

\section{REFERENCES}

\footnotetext{
${ }^{1}$ Tinto, V., 1975, "Dropouts from higher education: A theoretical synthesis of recent literature," A Review of Educational Research, v45, pp. 89-125.

${ }^{2}$ Veenstra, C.P., Dey, E.L., Herrin, G.D., 2009, “A model for freshman engineering retention," Advances in Engineering Education, Winter 2009, pp 1-33

${ }^{3}$ Spitzer, B., and Aronson, J., 2015, "Minding and mending the gap: Social psychological interventions to reduce educational disparities," British Journal of Educational Psychology, v 85 i1, March 2015, pp 1-18

${ }^{4}$ Yeager, D., Walton, G., and Cohen, G., 2013, “Addressing achievement gaps with psychological interventions," Phi Delta Kappan, v94 n5 pp62-65, Feb 2013

${ }^{5}$ McKinney, D., Denton, S.F., 2006, "Successfully crossing the cultural border between high school and college: Promoting a sense of belonging in a freshman seminar course," $36^{\text {th }}$ ASEE/IEEE Frontiers in Education Conference, Oct. 28-31, 2006

${ }^{6}$ Sevilla, K., and Paretti, M., 2014, "The development of a virtual socializer-based intervention targeting lowachieving second-year engineering students," Proceedings - Frontiers in Education Conference, Oct 22-24, 2014

${ }^{7}$ Smith, J., and Lucena, J., 2016, "Invisible innovators: how low-income, first-generation students use their funds of knowledge to belong in engineering," Engineering Studies, v8, no1, pp 1-26, DOI: 10.1080/19378629.2016.1155593
} 
8 Danielak, B.A., Gupta, A., and Elby, A., 2014, Journal of Engineering Education, v 103, n 1, p 8-44, DOI: 10.1002/jee.20035

${ }^{9}$ Kissinger, J., Campbell, R.C., Lombrozo, A., and Wilson, D., 2009, "The role of gender in belonging and sense of community," Proceedings - Frontiers in Education Conference, Oct 18-21, 2009

10 Judson, E., Ernzen, J., Chen, Y.C., Krause, S., Middleton, J., and Culbertson, R., 2015, "What is the effect of establishing programs that address sense of belonging on undergraduate engineering retention?", Proceedings Frontiers in Education Conference, Oct 21 - 24, 2015

${ }^{11}$ Litzler, E., and Smuelson, C., 2013, "How underrepresented minority engineering students derive a sense of belonging from engineering," ASEE Annual Conference and Exposition, Conference Proceedings, Jun 23-26, 2013 ${ }_{12}$ Wilson, D., Spring, D., and Hansen, L., 2008, "Psychological sense of community and belonging in engineering education," Proceedings of the Frontiers in Education Conference, Oct 22-25, 2008, Saratoga Springs, NY ${ }^{13}$ Dweck, C., 2007, "Mindset: The New Psychology of Success," Ballantine Books (an imprint and division of Penguin Random House LLC), ISBN 978-0-345-47232-8

${ }^{14}$ Hanks, B., McCauley, R., Murphy, L., Zander, C., and Simon, B., 2009, “CS1 students speak: advice for students by students," SIGCSE Bulletin, v41, n1, p 19-22

${ }^{15}$ Simon, B., Hanks, B., Murphy, L., Fitzgerald, S., McCauley, R., Thomas, L., and Zander, C., 2008, "Sayng isn't necessarily believing: Influencing self-theories in computing," Proceedings of the ACM Workshop on International Computing Education Research, pp 173-184, Sep 6-7, 2008

${ }^{16}$ Scott, M.J., and Ghinea, G., 2014, "On the domain-specificity of mindsets: the relationship between aptitude beliefs and programming practice," IEEE Transactions on Education, v57 n3, pp 169-74, August 2014

${ }^{17}$ Reid, K.J., and Ferguson, D.M., 2014, "Do design experiences in engineering build a 'growth mindset' in students?" Proceedings of the $4^{\text {th }}$ IEEE Integrated STEM Education Conference, Mar 8, 2014

${ }^{18}$ Cohen, G.L., Garcia, J., Apfel, N., and Master, A., 2006, "Reducing the Racial Achievement Gap: A SocialPsychological Intervention," Science, v 313, pp. 1307-1310

${ }^{19}$ Cohen, G.L., Garcia, J., Purdie-Vaughns, V., Apfel, N., and Brzustoski, P., 2009, "Recursive Processes in SelfAffirmation: Intervening to Close the Minority Achievement Gap," Science, v 324, pp. 400-403

${ }^{20}$ Walton, G.W., and Cohen, G.L., 2011, Supporting online material for "A brief social-belonging intervention improves academic and health outcomes of minority students," Science, v 331 n 1447

${ }^{21}$ Carnegie Math Pathways, Carnegie Foundation website, https://www.carnegiefoundation.org/inaction/carnegie-math-pathways/. Retrieved 2/3/2017

${ }^{22}$ Growth Mindset Assessment, PERTS website, https://survey.perts.net/share/toi. Retrieved 2/3/2017 